\title{
Study on the virus transmission based on data analysis of confirmed cases of 2019-nCoV coronavirus in China (II)
}

\author{
Peng Chen ${ }^{1}$ \\ School of Electronic Science and Engineering, Nanjing University, Nanjing, China \\ 210093
}

\begin{abstract}
This study is the continue work of the first analysis result posted in 31 Jan (https://doi.org/10.31219/osf.io/ek9n4).[1] This study was also based on the numerical analysis and general system evolution principle to analyze the number of confirmed cases and related data of 2019-nCoV coronavirus in China from 31 January to present (4 February) announced by the National Health Commission. The analysis result shows that during this period, the number of confirmed cases increased roughly according to a linear growth, the turning point is on 30 Jan. The main conclusion is that the spread of the virus has been effectively restricted since $23 \mathrm{Jan}$ in most region of China, that is, since Wuhan city and many other cities were put on lockdown. The lockdown strategy shows the power equivalent to near $80 \%$ of the people infected with the virus being captured by hospitals or isolated at home in the statistical equivalent. Based on these results, the spread of the virus can be expected to be slowdown due to the harsh lockdown strategy that leads to a slow decrease of the number of people who have not been diagnosed. It is suggested to maintain the lockdown strategy, especially in Hubei province, continue to concentrate the study on 2019-nCoV coronavirus transmission mechanism and then take targeted measures to comprehensively stop the virus infection.
\end{abstract}

Key words: 2019-nCoV, linear growth, virus transmission, system evolution principle

\footnotetext{
${ }^{1}$ E-mail: pchen@nju.edu.cn
} 


\section{Introduction}

Since 2020, the outbreak of 2019-nCoV coronavirus in the Wuhan region of China has caused great international attention. The confirmed cases is growing sharply through China and other countries. In order to limit the spread of the virus, various unprecedented and severe measures have been taken by Chinese government, such as "closing the city" in Wuhan city and following many other cities since 23 Jan.. The spread behavior of the virus in the early stage has been studied as the report posted on 31 Jan..[1] The main results are that the number of confirmed cases increased strictly according to a single exponential law, indicating that the virus transmission showed a chain reaction, and each generation has the same infectious power, so that the number of confirmed cases had risen sharply till to 30 Jan. by considering the average incubation period (7 days) of the virus. After 30 Jan., the patients from the newly confirmed cases should mainly be infected after the regional lockdown. Thus, how is the effect by the lockdown strategy becomes an urgent question to be answered right now, which is very important to fight with the virus.

In this work, the numerical analysis and general system evolution principle still are the main methods to study the transmission behaviour of the 2019-nCoV coronavirus, based on the number of confirmed cases and related data announced by the National Health Commission (NHC) of the People's Republic of China.[2,3] Although these methods cannot give a microscopic transmission mechanism of the 2019-nCoV, the results from the system evolution view can present the actual impact of the virus on our society. Finally, these results can help to know the mechanism of virus transmission and infection, furthermore to help fill the gaps in current countermeasures.

\section{Objects and methods}

This work studied the number of confirmed cases of the 2019-nCoV coronavirus in China to obtain the virus transmission pattern. The number of confirmed cases comes from data released by the NHC.[2,3] The number of confirmed cases from 31 Jan. to 4 Feb. was collected to study the law of virus transmission in this period.

The data analysis was based on purely mathematical methods. Based on the evolution of the confirmed cases and combined with the basic principles of multi-body system evolution in Physics, the basic inherent characteristics of virus transmission were analyzed. 


\section{Results and discussions}

According to the number of confirmed cases published on the website of the NHC, the raw data from 16 Jan. to 4 Feb. are listed in Table 1, where the prediction data from 31. Jan to 4 Feb. plotted in Ref 1 are also listed which had not been listed then.

Table 1 Number of confirmed cases and relative data

\begin{tabular}{|c|c|c|c|c|c|c|c|c|c|c|}
\hline Day & 1 & 2 & 3 & 4 & 5 & 6 & 7 & 8 & 9 & 10 \\
\hline Date & $\begin{array}{l}16 \\
\text { Jan }\end{array}$ & $\begin{array}{l}17 \\
\text { Jan }\end{array}$ & $\begin{array}{l}18 \\
\text { Jan }\end{array}$ & $\begin{array}{l}19 \\
\text { Jan }\end{array}$ & $\begin{array}{l}20 \\
\text { Jan }\end{array}$ & $\begin{array}{l}21 \\
\text { Jan }\end{array}$ & $\begin{array}{l}22 \\
\text { Jan }\end{array}$ & $\begin{array}{l}23 \\
\text { Jan }\end{array}$ & $\begin{array}{l}24 \\
\text { Jan }\end{array}$ & $\begin{array}{l}25 \\
\text { Jan }\end{array}$ \\
\hline $\begin{array}{l}\text { Confirmed } \\
\text { cases }\end{array}$ & 47 & 62 & 121 & 198 & 291 & 440 & 571 & 830 & 1287 & 1975 \\
\hline $\begin{array}{c}\text { Confirmed } \\
\text { daily incremen } \\
\text { outside Hubei }\end{array}$ & & & & & & & & & 277 & 365 \\
\hline $\begin{array}{c}\text { Total number } \\
\text { of close } \\
\text { contacts }\end{array}$ & & & & & & 2197 & 5897 & 9507 & 15197 & 23431 \\
\hline $\begin{array}{c}\text { Daily } \\
\text { increment of } \\
\text { close contacts } \\
\end{array}$ & & & & & & & 3700 & 3610 & 5690 & 8234 \\
\hline Day & 11 & 12 & 13 & 14 & 15 & 16 & 17 & 18 & 19 & 20 \\
\hline Date & $\begin{array}{l}26 \\
\text { Jan }\end{array}$ & $\begin{array}{l}27 \\
\text { Jan }\end{array}$ & $\begin{array}{l}28 \\
\text { Jan }\end{array}$ & $\begin{array}{l}29 \\
\text { Jan }\end{array}$ & $\begin{array}{l}30 \\
\text { Jan }\end{array}$ & $\begin{array}{l}31 \\
\text { Jan }\end{array}$ & $\begin{array}{c}1 \\
\text { Feb }\end{array}$ & $\begin{array}{c}2 \\
\text { Feb }\end{array}$ & $\begin{array}{c}3 \\
\text { Feb }\end{array}$ & $\begin{array}{c}4 \\
\text { Feb }\end{array}$ \\
\hline $\begin{array}{c}\text { Confirmed } \\
\text { cases }\end{array}$ & 2744 & 4515 & 5974 & 7711 & 9692 & 11791 & 14380 & 17250 & 20438 & 24324 \\
\hline $\begin{array}{l}\text { Prediction in } \\
\text { Ref } 1\end{array}$ & & & & & & 11700 & 14000 & 16000 & 18000 & 20000 \\
\hline $\begin{array}{c}\text { Confirmed } \\
\text { daily } \\
\text { increment } \\
\text { outside Hubei }\end{array}$ & 398 & 480 & 619 & 705 & 761 & 752 & 668 & 767 & 843 & 731 \\
\hline $\begin{array}{c}\text { Total number } \\
\text { of close } \\
\text { contacts } \\
\end{array}$ & 32799 & 47833 & 65537 & 88693 & 113579 & 136987 & 163844 & 189583 & 221015 & 252154 \\
\hline $\begin{array}{c}\text { Daily } \\
\text { increment of } \\
\text { close contacts }\end{array}$ & 9368 & 15034 & 17704 & 23156 & 24886 & 23408 & 26857 & 25739 & 31432 & 31139 \\
\hline
\end{tabular}

After 30 Jan., more and more useful data can be obtained or deduced, which allow us to conduct more studies based on Mathematics and Physics. Table 1 also presents some relative data, including the confirmed daily increment outside Hubei 
from 24 Jan. to present, total number of close contacts and daily increment of close contacts from 23 Jan to present.

The number of confirmed cases is plotted according to the number of days (16 Jan. is day 1) till to present (4 Feb.), and the vertical axis is the logarithmic coordinate, as same as in Ref 1 , shown in Figure 1.

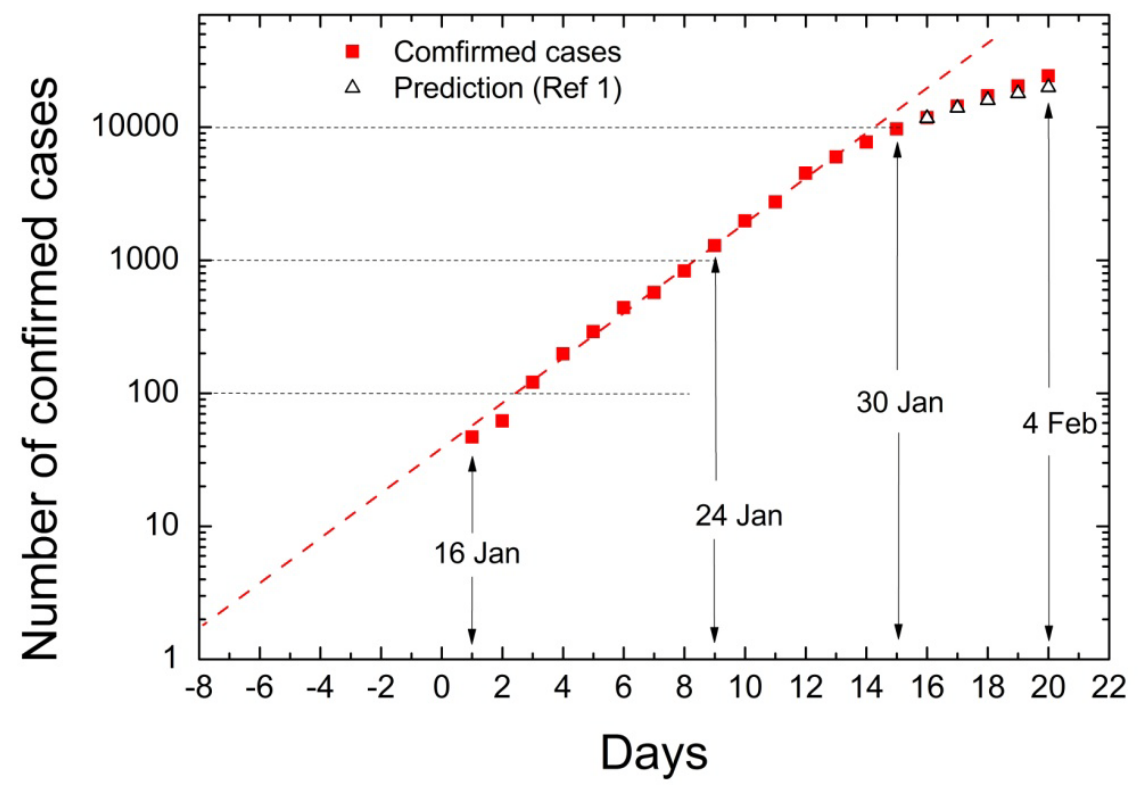

Figure 1 Relationship between the number of confirmed cases and the number of days on a logarithmic scale, where the open symbols in the figure are the predicted values.

It can be seen from Figure 1 that after 30 Jan., the number of confirmed cases has deviated from the single exponential rule, which is a clear signal for the change in the transmission mode of the virus. This virus has been known an average incubation period of about 7 days, thus, the growth of the confirmed cases after 30 Jan. presents the virus transmission after 23 Jan.. Please note that the lockdown strategy is executed on 23 Jan. Thus, it is expected that the virus transmission will change after the lockdown. In fact, it does.

In order to understand more clearly about the case increase mode, the data is re-plotted in Figure 2 in the linear coordinate system. It is clear that the number of confirmed cases after $30 \mathrm{Jan}$. is increasing roughly according to a linear growth. Obviously, the linear growth indicates that the system is running under a total different dynamics process from that by the single exponential growth. In principle, the linear growth presents that the system will grow by a fixed growth increment, 
different from the "chain reaction" which is by a fixed multiplication factor. Specific to this study, the multiplication factor can be 5 obtained in the previous report,[1] which has a close meaning as R0 in literatures. By considering the multiplication factor of 5, the fixed growth increment indicates that the lockdown strategy shows the power equivalent to $80 \%$ of people infected with the virus have been treated by hospitals or isolated at home statistically. The actual confirmed cases showed a little up deviation from the prediction, which means the actual percentage is a little lower than $80 \%$. In other words, once the actual confirmed cases is lower than the linear prediction, it means that more than $80 \%$ of people infected with the virus have been treated in the statistical equivalent.

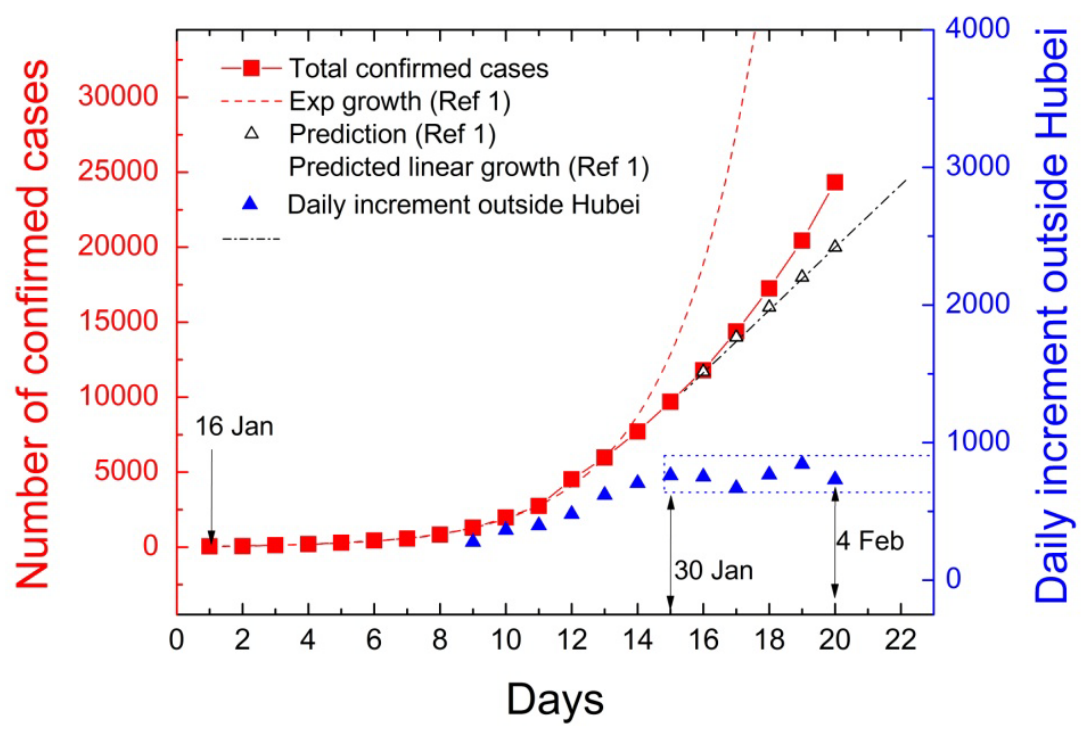

Figure 2 Relationship between the total/daily number of confirmed cases and the number of days in the linear coordinate system, where the open symbols are the predicted values.

The number of daily confirmed cases increment is another useful parameter that can indicate the spread of the virus. However, due to China's large area, it is difficult to predict that all regions will achieve the same degree of lockdown. The daily increment in China except for Hubei province has been analyzed as plotted in Figure 2. It is clear that the daily confirmed cases increment except for Hubei province is stable at around 800 cases, which is consistent with the linear growth. The reason for the up deviation of total cases is mainly because the daily confirmed cases in Hubei is continue to increase slowly, from below 2000 to over 3000 in fact. This situation can be understood. This outbreak first occurred in Hubei Province, where is the area with the most cases. Due to the relative lack of medical staff and facilities, it takes longer 
time to diagnose and treat patients. But in other parts of China, patients can get diagnosis and treatment in time, and with the help of various quarantine measures, the virus transmission has been significantly suppressed. 30 Jan. can be the first turning point.

In order to judge the spread of the virus in China on a larger scale, another set of data is used for analysis, i.e. the number of close contacts. The close contacts are those who have had close contact with a person infected with the virus and who have the potential to be infected, such as having a meeting in the same room, taking the same bus, etc. This total number of close contacts represents the largest population affected by the virus, and the data is plotted in Figure 3. The daily increment of the close contacts are also plotted in Figure 3.

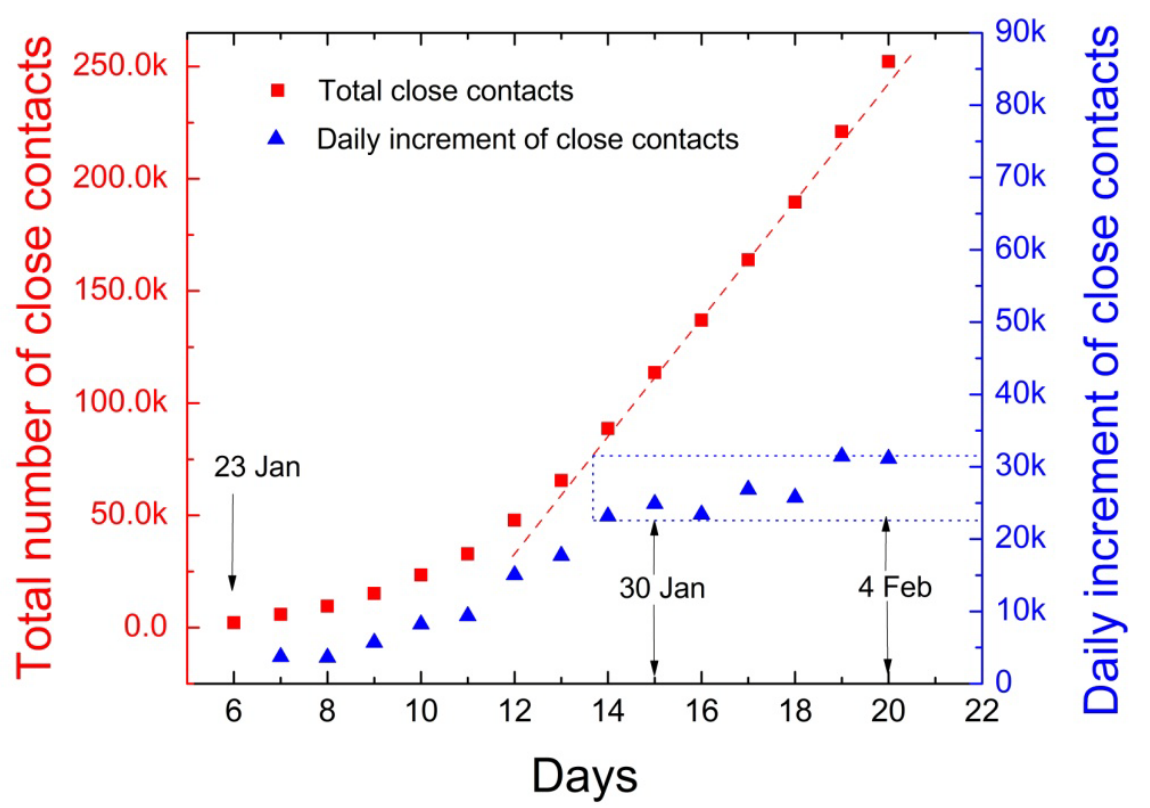

Figure 3 Relationship between the total/daily number of close contacts and the number of days.

According to the results in Figure 3, the total number of the close contacts showed a similar trend as the total confirmed cases. After 30 Jan, it showed a linear growth, and the daily increment seems to be stable around 26000, indicating that the multiple-affect of the 2019-nCoV in the population has been stopped. If the current lockdown strategy can be maintained for 2 more virus incubation periods which means most of people who were already infected were treated, then the number of potential candidates should be reduced, and finally the daily confirmed cases should decrease too. By that day, maybe 14 more days later, it will be the second turning point. 
The law of the "linear growth" proposed in this work can also be the basis for judging the spread of the coronavirus. Maintaining this law means that $80 \%$ patients have been captured in the statistical equivalent. When the number of confirmed cases falls below the linear growth, this means fewer and fewer patients are wandering out, which is good. Conversely, if the number of the confirmed cases is above the linear growth, it indicates that the spread of the virus has increased, maybe suggesting that the virus has mutated, or other something bad.

\section{Conclusions}

This study analyze the number of confirmed cases and related data of 2019-nCoV coronavirus in China from 31 January to present (4 February). It is found that the number of confirmed cases increased roughly according to a linear growth, the inflection point is on 30 Jan. The main conclusion is that the spread of the virus has been effectively restricted since 23 Jan in most region of China, that is, since Wuhan city and many other cities were put on lockdown. The lockdown strategy shows the power equivalent to $80 \%$ of people infected with the virus have been treated by hospitals or isolated at home in the statistical equivalent. Based on these results, the spread of the virus can be expected to be slowdown due to the harsh lockdown strategy that leads to a slow decrease of the number of people who have not been diagnosed. It is suggested to maintain the lockdown strategy, especially in Hubei province, continue to concentrate the study on 2019-nCoV coronavirus transmission mechanism and then take targeted measures to comprehensively stop the virus infection.

\section{Compliance and ethics}

The author(s) declare that they have no conflict of interest.

\section{References}

[1] Peng Chen, Study on the virus transmission based on data analysis of confirmed cases of the new-type coronavirus pneumonia in China, OSF Preprints, https://doi.org/10.31219/osf.io/ek9n4.

[2] http://www.nhc.gov.cn/xcs/yqtb/list_gzbd.shtml.

[3] http://www.nhc.gov.cn/xcs/xxgzbd/gzbd_index.shtml 